\title{
LA TRANSICIÓN Y ETA: LA FUGA DE SEGOVIA (1981)
}

\author{
Igor Barrenetxea Marañón
}

Universidad del País Vasco

«Los cineastas, consciente o inconscientemente, están al servicio de una causa»

(Ferro, 1995: 22)

\section{INTRODUCCIÓN: PREPARAR UNA FUGA}

A decir verdad, daba la impresión de que Imanol Uribe tenía una deuda pendiente con la sociedad vasca. A pesar del éxito fraguado por El proceso de Burgos (1979), Uribe no sació sus ansias de comprender y analizar el contexto vasco, por su enorme contenido dramático. Inspirado por el libro Operación Poncho de Ángel Amigo (Amigo, 1978)', decidió trasladar al cine, esta vez desde la recreación ficcionada, un episodio verídico: la fuga de la cárcel de Segovia de una treintena de presos, en su mayor parte miembros de ETA, en abril de 1976. Encomendó a Amigo la elaboración del guión y, además, como se había previsto un presupuesto elevado (de los ocho millones de pesetas que costó El proceso de Burgos se pasó a los sesenta), se acomodó a las labores de productor ejecutivo. Uribe contó también con las primeras subvenciones oficiales del Gobierno Vasco a una producción cinematográfica. Y otra parte se financió gracias al crédito concedido por varias entidades bancarias vascas.

Para completar el amplio reparto, se seleccionó entre una hornada de actores tanto del cine como del teatro (incluso del campo aficionado), algunos alumnos de la Escuela de Radio y Televisión vasca y como piezas claves se sumaron Patxi Bisquert e Imanol Gaztelumendi, que habían formado parte de la verdadera fuga.

Uribe pretendía ser lo más fiel posible a los hechos y al ambiente carcelario que vivieron los protagonistas, cumpliendo la afirmación de Rosenstone de que, en la medida de lo posible, «las películas pretenden que creamos que son la realidad» (Rosenstone, 1997: 49). Sin embargo, por razones obvias, no se pudo contar con las instalaciones de la cárcel de Segovia, como hubiera sido de desear, para dar una veracidad casi completa. Por el contrario, se contó con el antiguo colegio de Escolapios de Tolosa, además de otros escenarios ubicados en Orendain, Umieta, Segovia, Madrid, Zumárraga y Legazpi. Además, Uribe pudo encontrar y utilizar al mismo locutor que radió la fuga. Como ya lo había hecho en su momento con

1 Aunque el filme se limita a ilustrar la fuga que alcanzó más éxito hubo varios intentos previos. Así, es natural que la reconstrucción fílmica ofrezca algunas licencias características de la adaptación. 
El proceso de Burgos, Uribe eligió el Festival de San Sebastián de 1981 para presentar su segunda película, lo que atrajo enseguida muchas miradas de crítica y público. De hecho, su segundo film fue mucho mejor acogido ya que, al tratarse de una película de ficción, era más comercial, llegando a la cifra nada desdeñable de más de seiscientos mil espectadores. Además, recibió el premio de la FIPRESCl, en San Sebastián, y el primer premio en el Festival de Orleáns de 1982 (Zunzunegui, 1982: 22-28).

\section{EL CINE SE ACERCA A LA HISTORIA: ENTRE LA FICCIÓN Y LA REALIDAD}

«Fugarnos era una obligación, un compromiso con Euskadi»

(Amigo, 1978: 17)

La fuga de Segovia es la crónica de una fuga carcelaria de una treintena de presos, en su mayor parte miembros de ETA, en las postrimerías del franquismo. Pero, a pesar de que Uribe quiso ceñirse al guión de considerar la película de mera fuga carcelaria, hay elementos que radiografían una realidad paralela, la influencia de la Transición en Euskadi, sobre todo en lo concerniente al retrato de ETA.

En el momento en que se rodó la película aún se vivía una etapa en la que la lucha de ETA se idealizaba, minimizando la acción criminal. Sin embargo, a pesar de que no se incida mucho sobre ello, por primera vez se alude a una ETA dividida (sería en octubre de 1974) entre ETA militar y ETA político militar. Se rompía así una especie de tabú de enorme importancia política. ¿Tendría continuidad ETA después de Franco? Esta última, ETA (pm) ${ }^{2}$ acabará por renunciar a la violencia y constituirse, no sin tensiones, en partido político, Euskadiko Ezkerra. Pero no sería hasta 1982 cuando oficialmente se disolviera. El sector militar de ETA se vería justificado, en cambio, por Herri Batasuna (Llera, 2002: 121), lo que le llevaría a la continuidad de la lucha, aún con la llegada de la democracia. Tal antagonismo iba a revelar, finalmente, que la opción más dura es la que siempre ha acabado por primar en ETA y la que la ha llevado a la pervivencia. De hecho, las desavenencias entre ambos sectores en este contexto no eran notorias, ambos propugnaban la lucha armada y tenían la misma perspectiva de que Euskadi era un país ocupado. La diferencia venía más bien en el papel que jugaba la clase trabajadora en «el proceso revolucionario de Euskadi» (Jáuregui: 2000: p. 264). La primera lo valoraba desde el enriquecimiento mutuo; la segunda, sólo en el caso de que se alcanzase un cambio político relevante en España tras el franquismo.

Así, en el filme, la cárcel va a expresar el modo en el que se niega la identidad vasca a los presos (por ejemplo, el hecho de que no se les permita hablar en euskera ${ }^{3}$ ) y, por lo tanto, emblema de esa reivindicación nacional que amparaba la acción terrorista. De esa forma, se encuentra en este ambiente gris y lóbrego de la cárcel un lugar, no sin razón, reivindicativo por opresor. Esta realidad no se aleja de una verdad, como señala el periodista Luciano Rincón: «Jon Urrejelegi, de Zegama, preso en Segovia, no pudo hablar con sus padres des-

2 La escisión vino, en buena medida, motivada por la muerte de trece personas inocentes en una cafetería de Madrid.

3 Si bien, disponían de una biblioteca en euskera con unos trescientos volúmenes, por tanto, la licencia responde a una visión general sobre la represión antivasca anterior y no concreta de los hechos. 
pués de estar dos años sin verlos porque apenas entendían el castellano y les prohibieron la comunicación en euskera» (Rincón, 1985: 42). Escribe del mismo modo Isolina Ballesteros, «la situación política de Euskadi encuentra aquí su equivalente fílmico en la condición de encierro, aislamiento y supresión de derechos civiles y políticos» (Ballesteros, 2001: 130). Esta frase sintetiza el efecto que quiere crear la ambientación de La fuga de Segovia. Aunque, obviamente, no puede escaparse a una lectura política (pues los presos son miembros de ETA), tanto Amigo como Uribe quisieron omitir al máximo el contexto, para enfocar el drama como una película de acción. Sin embargo, eso no evita que al inicio del filme se haga una declaración de intenciones cuando se escucha la lectura de una carta de uno de los presos, José Elgueta, que se declara en huelga de hambre debido a que su país está sometido a la «represión fascista». La carta concluye exigiendo la «independencia y el socialismo para Euskadi y para todas las nacionalidades que lo soliciten» (Amigo, 1978: 97).

Estas palabras las debemos situar en las postrimerías del franquismo, como escribe De Pablo: «el franquismo respondió con la represión, a veces indiscriminada, lo que no hizo sino incrementar la solidaridad con ETA, tanto en la oposición antifranquista como a nivel internacional» (De Pablo, 2002: 109).

Lo que favoreció, precisamente, los intereses de las dos ETAs.

En la secuencia del filme, al final de la carta se expresa el deseo de que se conmute la pena de muerte de los miembros de ETA Juan María Otaegui y Juan Paredes Manot (Txiki), que serían fusilados en septiembre de 1975. Sin embargo, a pesar de que la movilización social e internacional había impedido - por ejemplo— que se llevasen a efecto las condenas a muerte de los etarras condenados en Burgos en 1970, en 1975 el régimen optó por hacer cumplir las penas, facilitando así a ETA y a los grupos violentos una justificación. Como indica José María Garmendia: «el franquismo estaba en las últimas, sin que apareciera con claridad una perspectiva de auténtica ruptura», por lo que sentencia «las condiciones para que la violencia pudiera perpetuarse no podían ser mejores» (Garmendia, 2000:168). Es, por ello, que la muerte de Franco no altera los planes de los reclusos, debido a que aún no había cambiado el régimen.

Si este arranque del filme hace pensar que Uribe recoge el testigo político dejado por El proceso de Burgos, esta idea se irá poco a poco diluyendo en un discurso que se irá abriendo hacia otros derroteros de suma importancia: el cambio paulatino que provoca la Transición en un sector de ETA y, por ende, un retrato de Euskadi. Así, en la ETA del filme se incide más en un discurso antifranquista que en uno propiamente antiespañol, debido a que, al acomodarse a los movimientos de liberación nacional, la dictadura se posicionaba como el enemigo a batir, el régimen fascista en esencia, no así los españoles (Jáuregui, 2000: 257). De ahí que no resulte chocante que el trato de los presos con los funcionarios de prisiones contenga más un tono cordial que de rebeldía. Esto se explicará porque no luchan contra los españoles sino contra el sistema opresivo y represivo del régimen franquista, ni más ni menos, no son las personas a las que se combate sino a la ideología que lo sustenta.

Un traveling que atraviesa significativamente el patio de la prisión desierta y en oscuridad se ve acompañado por las voces de los presos, antes aludidos, que anuncian el fin de los condenados a muerte. Esta narración puede traducirse muy bien en el hecho de cómo se solidarizan los presos entre ellos, al saber que todos pueden alcanzar ese mismo fin. Por eso, de algún modo, ante la situación se ven forzados a preparar la fuga como un medio de huir de esta todavía (in)justicia imperante. 
En otra escena, para poner de relieve la humillante situación en la que deben de vivir los presos, se celebra la boda entre José María Iturbe y su novia Nerea. Los testigos serán el jefe de la prisión y un funcionario, no la familia. Además, antes de dejar a solas al joven matrimonio, Nerea es desnudada, como medida de seguridad, lo que subraya esa situación de humillación y vergüenza (este hecho no aparece en el libro de Amigo, pero sintetiza bien tales emociones). La misma escena de la celebración de la boda es fría y descarnadamente amarga, no hay alegría ni un sucedáneo de amabilidad durante el acto. Y aunque, en esa forzada situación sus compañeros se alegran, en esa (a)normalidad, esta es motivada para desahogar la tristeza que les acompaña en su encierro. La escena es rota, nuevamente, por la tristeza que recorre los rostros de los familiares de los recién casados en el convite ante la ausencia de los novios.

Aunque se adelgacen las explicaciones políticas, eso no evita el codificar cambios en la definición de ETA. Así, al inicio del filme, los guardias descubren un primer intento de excavar un túnel y se alude a la idea de que haya un infiltrado entre ellos, refiriéndose al papel jugado por Mikel Lejarza «Lobo» en la detención de la cúpula de ETA político-militar y de sus comandos de Madrid y Barcelona (Amigo, 1978: 85)4. También, en otra escena, se menciona a los milis (miembros de ETA militar en el lenguaje de la época), a ETA militar y a los troskos, un sector de la izquierda radical trotskista. Cuando se prepara la fuga y quieren pactar un acuerdo entre las distintas facciones para saber quiénes van a escapar por el túnel, uno de los presos comenta que "los milis también firmarán», lo que incide en la existencia de esa ETA dividida antes comentada. No obstante, el filme no explica la diferencia y estos son los únicos elementos que nos hacen detectar una ETA no unitaria (Jáuregui, 2000: 253). Aunque, como explica Amigo, «en el interior de la prisión, sin embargo, los efectos de la crisis de ETA llegaban retardados y tamizados por el natural asilamiento a que estaban sometidos los presos» (Amigo, 1978: 34).

Pero los acontecimientos políticos que les rodean no invalidan la trama que han urdido para escapar mediante un túnel de la prisión (Amigo, 1978: 39). El hecho de que en la televisión (el medio que les permite tener conocimiento de lo que sucede fuera de esos muros) oigan la noticia de la «marcha verde» propugnada por Hassan II sobre el Sahara español, se convierte en la metáfora misma de un problema que el Gobierno franquista no supo cómo resolver (Contreras, 1983). Se intuye una comparación con el hecho de que tampoco el franquismo supiera cómo enfrentarse a la violencia de ETA: al contrario, la incapacidad del régimen fue lo que permitió otorgarle a la lucha armada un simbolismo que ha persistido aún con la llegada de la democracia. La muerte de Franco, que reciben con algarabía, no les hace renunciar a la idea de fugarse, ya que aún desconfían de que se produzca un verdadero cambio del sistema tras el fallecimiento del dictador y porque, además, no perdían nada intentándolo (Rincón, 1985: 52).

El filme, a pesar de su arranque -insistimos_ rebaja su tinte político. Cuando los presos escuchan por la radio el secuestro del empresario guipuzcoano Ángel Berazadi ${ }^{5}$, en ningún momento se alude a la banda y cuando se nos muestra al comando que, fuera de la prisión, está preparando la fuga, uno de ellos confiesa que la gente de Madrid «es maja», algo difícil de creer en unos activistas que están llevando a cabo una lucha de independencia contra España (Amigo, 1978: 152).

4 De hecho, eso impidió el primer intento de fuga ya dispuesto.

5 Asesinado finalmente por ETA el 7 de abril, por el impago de su rescate —estaba vinculado al PNV_- 
En el momento crucial previo a la fuga, el comité que la organiza incluye en la lista de los que han de fugarse a un miembro del Partido Comunista catalán, lo que subraya el talante internacional de la ETA antifascista. De hecho, es llamativo que la tarde en la que celebran con una comida la huida se cante en el comedor «El rossinyol», que culmina con un «Visca Cataluña!», generalizado por parte de todos los presos, con mucho entusiasmo. No es una contradicción en aquel contexto de pugna contra el régimen, puesto que existe una perspectiva común de que hay una lucha por «los derechos de los pueblos y las naciones, que forman el Estado español» (Letamendia, 1994: 353). Aunque Ballesteros (2001: 131) considera un tanto extraño que se cante una canción catalana, en vez de una canción vasca, olvida que nos encontramos ante la ETA idealizada. El éxito alcanzado por la movilización social a favor de los miembros de la banda juzgados en Burgos reverberaba en esta codificación del apoyo que ETA recibía de la sociedad vasca. La lucha se entendía más en términos políticos que militares, de ahí el simbolismo positivo que ostentaba (Tusell, 2002: 491). Porque, con todo, como escribe De Pablo, «lo cierto es que ETA fue el principal protagonista de la oposición en el País Vasco desde mediados de los años 60», y fue lo que «más preocupó a las autoridades franquistas» (De Pablo, 2002: 108), de ahí que aglutinase la mayor parte de una aguerrida simbología heroica. Aun con todo, como se recrea en el filme, a ETA también le interesó, en ese contexto, cultivar una imagen positiva. Así, cuando dos activistas secuestran un camión a punta de pistola para la huida (Amigo, 1978: 163), el conductor afirma con sorprendente calma: «Ah, sois de la ETA». Del mismo modo, tras la fuga, se compensa a los dueños de un chalet por los estropicios que les han causado. La lucha es contra aquellas fuerzas reactivas del régimen, no contra los españoles.

\section{LA FUGA: CARRERA HACIA LA LIBERTAD}

Finalmente, llega el día de la esperada fuga. Se evaden de la prisión 29 presos: entre ellos dos trotskistas y dos nacionalistas catalanes, lo que refuerza esa convicción de que la fuga tiene un mensaje más de lucha de clase que estrictamente vasquista. Tras salir del túnel, les recoge el camión que han secuestrado los miembros de ETA del exterior y se dirigen hacia la frontera. Sin embargo, el guía que les debía esperar para pasarlos al otro lado no aparece, debido a un error en la comunicación (Amigo, 1978: 187). Nerviosos, deciden no esperar y seguir adelante, amparados por la densa niebla, con tan mala suerte que tropiezan con una patrulla fronteriza de la Guardia Civil. En el enfrentamiento, los fugados se dispersan por el monte y se fraccionan en diferentes grupos que corren una suerte dispar (Amigo, 1978: 191).

Uno de los grupos se refugia en un pueblo pero es detenido, al igual que uno de los presos heridos, que se refugia en un caserío. El segundo, que vaga por el monte, acaba en manos de la patrulla policial, pero el miembro del Partido Comunista catalán, Oriol, debido a un disparo accidental, cae muerto (Amigo, 1978: 2005) ${ }^{6}$. Esta escena, según incide Ballesteros, es «la culminación de una estrategia de apoyo» a la causa nacionalista por parte del filme de Uribe (Ballesteros, 2001: 131). Pero, críticamente, debemos de situarnos en un momento histórico en el que el régimen no reconocía ninguna nacionalidad salvo la española. El filme

6 De hecho, en la obra Operación Poncho no es tan magnánima y se señala «la guardia civil dio muerte a Oriol», lo que señalaría que no tuvo nada de accidente. 
constituye, con ello, la radiografía de una realidad, en la que su brutalidad y su actitud represiva fueron bastante elocuentes. El tercer grupo, el que se refugia en un chalet que está deshabitado, logra finalmente alcanzar la costa desde donde son trasladados en barco a Francia. Sin embargo, una vez allí son internados en la isla de Yeu por las autoridades francesas (Amigo, 1978: 232). Sólo una vez concedida la amnistía logran retornar a España.

En el epílogo del filme, se cortaron unos minutos de filmación en su versión comercial, no así en su presentación en el Festival de San Sebastián, donde se proyectó una versión íntegra. Uribe justificó el corte de 17 minutos por razones de tipo político: adujo que era «un análisis muy sectario, muy desde el punto de vista de Euskadiko Ezkerra» (Angulo, 1994: 120). Para Zunzunegui «la famosa escena era absolutamente genérica en sus afirmaciones del tipo, si las cosas cambian tendrán que cambiar las formas de lucha, etc. (Zunzunegui, 1985: 260). Ahora bien, habríamos de considerar que, si bien Uribe no quiso posicionarse, esa alusión directa al cambio de las formas de lucha sí era significativa, porque implicaba denunciar la violencia. El apoyo a un abandono de las armas por parte de ETA hubiera significado un compromiso político mayor de lo que eran las intenciones iniciales de Uribe. Aunque, como escribe Mario Onaindía respecto al intento de racionalizar los fines de ETA militar en aquellos años a la salida del franquismo, «en nada cambió el funcionamiento de la organización» (Onaindía, 2003: 221). De hecho, este antiguo dirigente de ETA político-militar cuenta cómo en las manifestaciones se gritaba que «la amnistía no se negocia».

Uribe intenta casar todos los complicados elementos para darle una coherencia al filme. Pero las circunstancias políticas habían cambiado en septiembre de 1981, en el momento del estreno: en 1979 se había aprobado el Estatuto de Gernika y al año siguiente se produjeron las primeras elecciones al Parlamento vasco. Quién mejor que Onaindia para señalar: «La película, con todo, mantiene un tono épico de lucha de todos los vascos contra la dictadura franquista, que ya se daba únicamente en la pantalla» (Angulo, 1994: 48). A fin de cuentas, el protagonismo dado a los presos de ETA en el filme sólo podría explicarse desde su existencia «como organización carismática, la santidad de sus componentes proporcionada por su cercanía a la causa» (Mata López, 1993: 139). Esta mitificación parecía empezar a desmentirse como falsa, ante sus campañas de auténtico terror en los años que continuaron a la llegada de la democracia: 68 muertos en 1978, 76 en 1979, 91 en 1980. Y aunque, como indica Rincón, «las campañas proamnistía son uno de los ejes de la magnificación de la imagen de ETA» (Rincón, 1985: 42), tampoco la actitud favorable del Gobierno español con los presos de ETA en esos años empujó a la organización a cambiar de medios para defender sus posturas violentas, pues ETA «carece de mecanismos ideológicos y teóricos para poder encarar con garantías de éxito su abandono de la violencia» (Angulo, 1994: 216). De hecho, pensemos cómo concluye su obra Ángel Amigo, indicando que, para «el primer aniversario de la fuga, todos los participantes estaban en libertad, amnistiados» (Amigo, 1978: 236). Sin embargo, la historia de ETA continuó adelante.

\section{A MODO DE CONCLUSIÓN: ETA, DEL HEROÍSMO A LA PERVERSIÓN}

No hay duda de que el cine permite abordar el pasado desde el presente: como afirma Marc Ferro, es la radiografía de un tiempo social pero, a la vez, permite evaluar un pasado que nos ayuda a establecer juicios distintos. En palabras de Zunzunegui: «De la noche a la mañana, Imanol Uribe pasaba de ser considerado el cineasta de Herri Batasuna (EI proceso 
de Burgos) a serlo de Euzkadiko Ezkerra (La fuga de Segovia)» (Zunzunegui, 1985: 259). Ahora bien, el problema en el filme es que se da a entender, al final, que con la amnistía de presos la cuestión vasca queda solucionada, quizás debido a la dinámica que había provocado que una parte de ETA renunciase a la violencia a favor de vías políticas y democráticas. $\bigcirc$, simplemente, porque le fue difícil en ese contexto a Uribe perfilar otro final para su película.

No era de extrañar, pues desde ciertos sectores nacionalistas se consideró que el Estatuto de Guernica no era sino un parche a la Transición que, aún, debía de ser llevada a cabo en Euskadi. No lo olvidemos: el PNV había quedado fuera de la ponencia constitucional y la amnistía de presos vascos afectaba a presos de una banda terrorista que seguía en activo y que había incrementado su número de acciones (Llera, 2002: 120). El filme tampoco podía analizar una situación compleja, en donde la existencia de un latente pluralismo político en Euskadi impedía una definición de posiciones políticas concretas, por lo que había que adelgazar, políticamente hablando, la propuesta fílmica con un simplista, si bien intencional, final conciliatorio.

El filme, al inspirarse en unos hechos que se vivieron en los complicados años 70, en ese lapso de tiempo entre la muerte de Franco y la Transición, bebía de unas circunstancias que, ante la pervivencia de una parte de ETA, parecían convertirse en un modo de volver a idealizar la lucha armada. Aunque, como hemos visto, hay alusiones a la partición de ETA, no se insiste sobre la cuestión, sosteniéndose el recurso ingrávido de que siempre es una y su lucha ostenta el simbolismo de la permanente reivindicación del pueblo vasco por su identidad. Así que, al intentar canalizar el discurso del filme desde una perspectiva política a otra más social y reducir los aspectos ideológicos a aspectos incidentales, no acabara por encontrar su justo punto de llegada. Por todo ello, es natural que, a pesar de que el filme parece cerrarse con la amnistía general de presos, no se alcanza a establecer la distinción entre aquellos que optaron por el abandono de las armas y los que optaron por continuar con ellas. Lo que es lo mismo: reflejar más nítidamente que existió una parte de ETA que rompió con la violencia y otra que decidió seguir recurriendo a ella. Sin duda, habría adquirido un mayor relieve esta distinción porque hubiera permitido, por primera vez, enfatizar la visión no unitaria de ETA en la pantalla y, por lo tanto, en la imaginería abertzale.

Aún con todo, La fuga de Segovia se convierte en un filme determinado por un contexto político en el que se hacía viable una reivindicación de la identidad y de la nación vasca desde posiciones no violentas, ante la aprobación del Estatuto de Gernika y la reinstauración de un sistema democrático en el que retornaba el pluralismo político. Pero Uribe parecía estar todavía preso de los convencionalismos que le marcaron en El proceso de Burgos e influido por el espíritu del libro en que se basaba La fuga de Segovia, apela a un espíritu de resistencia porque la lucha contra el régimen así lo justificaba. Pero ese tiempo ya había pasado. El intento de Uribe de influir en ETA positivamente se estrelló contra la realidad de su continuidad. Finalmente, Uribe sólo rompería definitivamente con su visión heroica de ETA cuando rodó años más tarde Días contados (1994). La lucha de ETA se había convertido, para entonces, en todo menos en algo heroico y en cualquier caso sucio y marginal.

\section{BIBLIOGRAFÍA}

AMIGO, Ángel, Operación Poncho: Las fugas de Segovia, Bilbao, Hordago, 1978. ANGULO, Jesús, HEREDERO, Carlos F., REBORDINOS, José Luis, El cine de Imanol Uribe, San Sebastián, Filmoteca Vasca, 1994. 
BALLESTEROS, Isolina, Cine (Ins) urgente, Madrid, Fundamentos, 2001.

CONTRERAS GRANGUILLHOME, Jesús, La independencia del Sáhara Occidental, México, Federación Editorial Mexicana, 1983.

FERRO, Marc, Historia contemporánea y cine, Barcelona, Ariel, 1995.

GARMENDIA, José $\mathrm{M}^{a}$, «ETA: Nacimiento, desarrollo y crisis», en Antonio Elorza (coord.) La historia de ETA, Madrid, Temas de hoy, 2000, pp. 77-170.

JÁUREGUI, Gurutz: «ETA: Orígenes y evolución ideológica y política», en Antonio Elorza (coord.), La historia de ETA, Madrid, Temas de hoy, 2000, pp. 171-266.

LETAMENDIA, Francisco, Historia del nacionalismo vasco y de ETA. ETA en el franquismo (1951-1976). Donostia-San Sebastián, R \& B, 1994.

LLERA RAMO, Francisco J, «La Transición y la autonomía actual», en José Luis de la Granja y Santiago de Pablo (coords.), Historia del País Vasco y Navarra, Madrid, Biblioteca Nueva, 2002, pp. 117-146.

MATA LÓPEZ, José Manuel, El nacionalismo vasco radical, Bilbao, Universidad del País Vasco, 1993.

ONAINDÍA, Mario, Guía para orientarse en el laberinto vasco, Madrid, Temas de hoy, 2003.

PABLO, Santiago de, "La dictadura franquista y el exilio», en José Luís de la Granja y Santiago de Pablo (coords.), Historia del País Vasco y Navarra, Madrid, Biblioteca Nueva, 2002, pp. 89-116.

RINCÓN, Luciano, ETA (1974-1984), Barcelona, Plaza y Janés, 1985.

ROSENSTONE, Robert A., El pasado en imágenes, Barcelona, Ariel Historia, 1997.

TUSELL, Javier., "Los grandes procesos penales de la época de Franco. Desde la posguerra a Grimau y el proceso de Burgos», en MUÑOZ MACHADO, Santiago (ed.); Los grandes procesos de la Historia de España. Barcelona, Crítica, 2002, pp. 484-493.

ZUNZUNEGUI, Santos, «Un film no es un obús», Contracampo, núm. 27, Año IV, enero/febrero, 1982, pp. 22-28.

ZUNZUNEGUI, Santos, El cine en el País Vasco, Bilbao, Diputación Foral de Vizcaya, 1985. 